\title{
High serum creatinine in early life of preterm infants predicts the severe retinopathy of prematurity: a retrospective single-centre study
}

\section{Seong Phil Bae}

Soonchunhyang University

Sung Shin Kim ( $D$ sungshin1201@gmail.com )

Soonchunhyang University

\section{Won-Ho Han}

Soonchunhyang University

Ho Kim

Soonchunhyang University

Ji Won Koh

Soonchunhyang University

Jun Hwan Song

Soonchunhyang University

\section{Soo Yeon Park}

Soonchunhyang University

\section{Research Article}

Keywords: Infant, Very Low Birth weight, Retinopathy of Prematurity, Risk Factor, Infant, Premature

Posted Date: February 17th, 2021

DOl: https://doi.org/10.21203/rs.3.rs-198997/v1

License: (9) This work is licensed under a Creative Commons Attribution 4.0 International License. Read Full License 


\section{Abstract \\ BACKGROUND}

Hypoxia and anemia are among the risk factors for retinopathy of prematurity (ROP). The kidneys are important organs that sense oxygen levels and regulate red blood cell synthesis via erythropoietin production. We investigated the contribution of abnormal renal function (reflected by serum creatinine [SCr] levels) to severe ROP in very low birth weight (VLBW) infants.

\section{METHODS}

In the present study, we enrolled 242 VLBW infants of gestational age (GA) ranging between 25 and 32 weeks who were admitted at Soonchunhyang Cheonan University Hospital between Nov 2014 and Dec 2019. The cut-off value for normal SCr for each GA group based was defined as 95th percentile of SCr based on a reference chart developed in a previous study. Risk factors for ROP requiring treatment were analyzed using logistic regression.

\section{RESULTS}

Of the 242 infants, 63 (26\%) were high SCr group and 30 (12.4\%) infants had ROP requiring treatment. GA (odds ratio $0.38,95 \%$ confidence interval $0.23-0.61$ ) and high SCr group (4.68 [1.10-19.90]) were independent factors for ROP requiring treatment.

\section{CONCLUSIONS}

In VLBW infants, high SCr within the first 4 weeks after birth is one of the risk factors for ROP requiring treatment.

\section{Background}

Retinopathy of prematurity (ROP) is characterized by the suppression of retinal neuronal and vascular development in premature infants. It has been reported to result from inadequate levels of a variety of components including erythropoietin (Epo), vascular endothelial growth factor (VEGF), omega-3 polyunsaturated fatty acids and insulin-like growth factor- $1 .{ }^{1}$

Previously, ROP has been associated with anemia and blood transfusion during the early life of preterm infants. ${ }^{2,3}$ In recent animal studies, premature renal function or oxidative renal injury has also been shown to affect the expression of oxygen-regulated factors such as Epo and VEGF, resulting in anemia of prematurity and oxygen-induced retinopathy. ${ }^{4,5}$ Therefore, given the mechanism of renal regulation of red 
blood cell synthesis via Epo by sensing hypoxia, anemia, and dissolved oxygen, premature or impaired renal function could be an early and significant risk factor for ROP development.

Serum creatinine $(\mathrm{SCr})$ is the most common and readily available marker of renal function. However, assessment of renal function in preterm infants and newborns using $\mathrm{SCr}$ is limited by several factors; $\mathrm{SCr}$ is affected by gestational age (GA) and fetal muscle mass. In addition, a few days after birth, newborn $\mathrm{SCr}$ reflects maternal $\mathrm{SCr}$ level, and thus the range of normal $\mathrm{SCr}$ varies widely. ${ }^{6}$

A recent study developed reference charts for SCr level of clinically stable preterm infants in each GA category. ${ }^{7}$ Based on the reference values, $\mathrm{SCr}$ level above the 95 th percentile was defined as a surrogate marker for abnormal renal function.

In this study, we investigated the contribution of abnormal renal function to the development of ROP. We hypothesized that abnormal renal function within the first 4 weeks after the birth of very low birth weight (VLBW) infants contributed significantly to the incidence of ROP requiring treatment.

\section{Methods}

\section{Study population}

This was a retrospective cohort study of 242 VLBW infants of GA between $25^{+0}$ and $32^{+6}$ weeks who were admitted at the Soonchunhyang Cheonan University Hospital between Nov 2014 and Dec 2019. The exclusion criteria was: infants with major congenital anomalies; those who died before the postmenstrual age (PMA) of 36 weeks; infants transferred to another hospital during hospitalization; and those born to mother with end-stage renal failure (ESRD). The study conformed to the ethical guidelines of the World Medical Association Declaration of Helsinki and was approved by the Institutional Review Board (IRB) of Soonchunhyang University Cheonan Hospital (IRB No. 2020-02-026-002).

Creatinine measurement

Routine blood samples were collected at birth and at 3 and 7 days after birth at the neonatal intensive care unit of the hospital. Subsequently, blood sampling was performed every 1-2 weeks, depending on the clinical condition of the infants. If infants were clinically unstable, additional sampling was performed at the discretion of the neonatologists. SCr was measured using an alkaline picrate rate-blanked method with compensation via Jaffe method on Cobas 8000 c702 (Roche Diagnostics, Mannheim, Germany); rate blanking was used to minimize interference by bilirubin while compensation was used to correct nonspecific reaction caused by serum pseudo-creatinine chromogens, including proteins and ketones. This method is traceable to isotope dilution mass spectrometry reference measurement procedure.

All available values for SCr levels were retrieved. From 5 days to 4 weeks after birth, SCr values were determined weekly during the first 4 weeks after birth and registered. If more than two blood samples 
were obtained in a week, the highest SCr level was selected each week, and the SCr level was selected at least two days after the level registered during the previous week.

The high SCr group was defined as VLBW infants with registered SCr levels above the $95^{\text {th }}$ percentile, which was the cut-off value in the reference chart from 5 days to 4 weeks after birth for each GA group. ${ }^{7}$

ROP screening and treatment

Screening tests were performed according to the guidelines of the American Academy of Pediatric Ophthalmology and the Association for Pediatric Ophthalmology and Strabismus with some modifications. ${ }^{8}$ ROP staging was based on the revised guidelines of the International Classification of ROP. ${ }^{9}$ Treatment was performed according to the recommendations of the Early Treatment for ROP Cooperative Group. ${ }^{10}$ One infant received anti-vascular endothelial factor therapy by intra-vitreal injection, while the others received laser photocoagulation.

General management of infants

Incubators were controlled to maintain a neutral thermal temperature of $37 \pm 0.5^{\circ} \mathrm{C}$, with a relative humidity of $90 \%$, which was gradually decreased as the skin matured.

Intravenous fluid volume on the first day of birth was $60-80 \mathrm{~mL} / \mathrm{kg} / \mathrm{d}$, increasing to $100-120 \mathrm{cc} / \mathrm{kg} / \mathrm{d}$ on the third day of birth. Parenteral nutrition was administrated within the first $48 \mathrm{~h}$. Enteral feeding via orogastric tube was commenced during the first $24 \mathrm{~h}$ of life unless the condition of the infants was unstable.

VLBW infants born before 29 weeks of GA and weighing less than $1250 \mathrm{~g}$ were treated with a prophylactic surfactant. Infants who were ineligible for prophylactic surfactant therapy received the surfactant as soon as possible following the onset of respiratory distress syndrome (RDS). Hypotension was controlled by dopamine, dobutamine, and hydrocortisone. In the case of patent ductus arteriosus (PDA), no prophylactic treatment was given. In hemodynamically significant PDA, intravenous ibuprofen (Pedea ${ }^{\circledR}$; Orphan Europe, Paris, France) was administrated. If two cycles of intravenous ibuprofen had no effect, surgery was performed.

Statistical analysis

Categorical data were analyzed using a chi-square test or Fisher's exact test, and continuous data were analyzed by $t$ tests and Mann-Whitney tests. Variables with a significance of $p \leq 0.1$ in the univariable analysis were subjected to multivariable logistic regression analysis, and the level of significance was set at $p<0.05$.

All statistical analyses were performed using SPSS version 25.0 (IBM Corp., Armonk, NY, USA) and R package version 3.3.1 (The R Foundation for Statistical Computing, Vienna, Austria). 


\section{Results}

Of the 295 VLBW infants, 242 were enrolled in this study. The following infants were excluded: 33 who died before PMA of 36 weeks, 5 with congenital anomalies, 13 who were transferred to other hospitals and 2 infants who were born to a mother with ESRD (Fig. 1). All participants were screened for ROP, and 30 infants were diagnosed with ROP requiring treatment. Medical records of VLBW infants and mothers were retrospectively evaluated.

The high SCr group showed significantly lower GA and birth weight (BW) than normal SCr group (Table 1). SCr levels at birth in the high SCr group were lower than in the normal SCr group. In the normal SCr group, the peak SCr levels were mostly observed at 1 week after birth, but in the high SCr group, the peak was observed all through to 2 weeks after birth. Thereafter, a more rapid decline was observed (Fig. 2). 
Table 1

Demographic characteristics of the study population.

High SCr group

$(n=63)$
Normal SCr group

$(n=179)$

Infant

Gestational age (weeks)

Birth weight

Multiple gestations

In vitro fertilization

Sex, male

Hemoglobin at birth

Hematocrit at birth

SCr at birth

C-reactive protein at birth

Period of first transfusion (days)

No. of phlebotomies until first transfusion

Transfusion within first 7 days

Transfusion during $7-30$ days

Total transfusions

Nephrotoxic medication

Postmenstrual age at discharge

Body weight at discharge

Hemoglobin at discharge

Hematocrit at discharge

$\mathrm{SCr}$ at discharge

C-reactive protein at discharge

Maternal factors
$27.86(26.86-29.29) \quad 29.86(29-31.29) \quad<0.001$

$1010(840-1220) \quad 1300(1130-1420) \quad<0.001$

$24(38.1)$

$84(46.9)$

0.225

$19(30.2)$

$57(31.8)$

0.804

$33(52.4)$

$84(46.9)$

0.456

$15.65(14.48-17.03) \quad 16(15.1-17.28)$

0.141

$46.95(43.23-50.85) \quad 48.0(44.43-52.43)$

0.188

$0.45(0.39-0.56)$

$0.5(0.4-0.6)$

0.013

$0.1(0.03-0.44)$

$0.12(0.05-0.36)$

0.526

$8.5(5-12)$

$16(6-26)$

0.001

$4(3-5)$

$5(3-6)$

0.012

$0(0-1)$

$0(0-0)$

$<0.001$

$1(1-2)$

$0(0-1)$

$<0.001$

$3(2-5)$

$1(0-2)$

$<0.001$

55 (87.3)

40.7 (39.29-42.43)

$122(68.2)$

0.003

$2720(2500-3000)$

38.42 (37.57-39.29)

$<0.001$

$2720(2500-3000)$

2510 (2330-2750)

$<0.001$

11.05 (9.7-12.53)

10.9 (10.0-12.1)

0.300

33.75 (30.38-37.58)

$33.45(30.23-36.98)$

0.247

$0.2(0.17-0.25)$

$0.22(0.2-0.3)$

0.001

$0.27(0.1-0.79)$

$0.29(0.14-0.70)$

0.739

The data are presented as medians (interquartile range) or $n(\%)$.

$S C r$ serum creatinine, $P R O M$ premature rupture of the membranes, ANS antenatal steroid, PDA patent ductus arteriosus, $R O P$ retinopathy of prematurity, $B P D$ bronchopulmonary dysplasia. 


\begin{tabular}{|llll|}
\hline & $\begin{array}{l}\text { High SCr group } \\
(\boldsymbol{n}=63)\end{array}$ & $\begin{array}{l}\text { Normal SCr group } \\
(\boldsymbol{n}=179)\end{array}$ & $\boldsymbol{p}$ value \\
\hline Maternal age & $32(29-35)$ & $33(29.75-36)$ & 0.069 \\
\hline Maternal SCr before delivery & $0.5(0.4-0.53)$ & $0.5(0.4-0.6)$ & 0.499 \\
\hline Gestational diabetes mellitus & $13(20.6)$ & $40(22.3)$ & 0.778 \\
\hline Preeclampsia & $8(12.7)$ & $43(24.0)$ & 0.058 \\
\hline Thyroid disorders & $9(14.3)$ & $22(12.3)$ & 0.684 \\
\hline PROM & $7(11.3)$ & $20(11.2)$ & 0.980 \\
\hline Not treated ANS & $21(33.3)$ & $66(36.9)$ & 0.615 \\
\hline Oligohydramnios & $15(25)$ & $40(22.6)$ & 0.703 \\
\hline Cesarean section & $59(93.7)$ & $165(92.2)$ & $<0.999$ \\
\hline Comorbidities & & & 0.087 \\
\hline Apgar score less than 7 at 5 minutes & $29(46.8)$ & $55(34.4)$ & 0.024 \\
\hline Respiratory distress syndrome & $63(100.0)$ & $165(92.2)$ & $<0.001$ \\
\hline Sepsis & $14(22.2)$ & $10(5.6)$ & $<0.001$ \\
\hline Surgically closed PDA & $22(34.9)$ & $11(6.1)$ & 0.001 \\
\hline Necrotizing enterocolitis & $6(9.5)$ & $1(0.6)$ & $<0.001$ \\
\hline Treated ROP & $21(33.3)$ & $9(5.0)$ & $<.001$ \\
\hline Moderate-to-severe BPD & $13(20.6)$ & & \\
\hline The data are presented as medians (interquartile range) or $n(\%)$. & & \\
\hline $\begin{array}{l}\text { SCr serum creatinine, } P R O M \text { premature rupture of the membranes, } \\
\text { ductus arteriosus, } R O P \text { retinopathy of prematurity, BPD bronchopulmonary dysplasia. }\end{array}$ & \\
\hline
\end{tabular}

There was no difference in hemoglobin and hematocrit at birth, however, the high SCr group received the first transfusion earlier, and the frequency of transfusion in the first month was higher than in the normal SCr group.

Within 4 weeks after birth, the use of nephrotoxic drugs such as ibuprofen, aminoglycoside, amphotericin, and vancomycin was higher in the high SCr group than in the normal SCr group. At discharge, the high $\mathrm{SCr}$ group showed a lower $\mathrm{Cr}$ level than the normal $\mathrm{SCr}$ group. There were no significant differences in maternal related factors. 
Comorbidities, including RDS, sepsis, surgically closed PDA, necrotizing enterocolitis, ROP requiring treatment, and moderate-to-severe bronchopulmonary dysplasia, was significantly higher in the high $\mathrm{SCr}$ group than in the normal SCr group.

In the univariable analysis of risk factors for ROP requiring treatment, infants in the ROP group had lower GA and BW, and the incidence of multiple gestations was also lower than in the non-ROP group (Table 2). Among the maternal factors, cesarean section showed a significant difference between groups. 
Table 2

The risk factors for ROP requiring treatment.

\begin{tabular}{|c|c|c|c|}
\hline & $\begin{array}{l}\text { ROP } \\
(n=30)\end{array}$ & $\begin{array}{l}\text { No-ROP } \\
(n=212)\end{array}$ & $p$ value \\
\hline \multicolumn{4}{|l|}{ Infant } \\
\hline Gestational age (weeks) & $27.1(25.9-27.6)$ & $29.9(28.9-31.1)$ & $<0.001$ \\
\hline Birth weight & $905(837.5-1095)$ & $1280(1110-1420)$ & $<0.001$ \\
\hline Small for gestational age ${ }^{a}$ & $0(0.0)$ & $8(3.8)$ & 0.601 \\
\hline Multiple gestations & $8(26.7)$ & $100(47.2)$ & 0.039 \\
\hline In vitro fertilization & $6(20.0)$ & $70(33.0)$ & 0.157 \\
\hline Sex, male & $19(63.3)$ & $98(46.2)$ & 0.083 \\
\hline \multicolumn{4}{|l|}{ Maternal factors } \\
\hline Maternal age & $33(29-34.3)$ & $33(29.3-36)$ & 0.507 \\
\hline Gestational diabetes mellitus & $4(13.3)$ & $49(23.1)$ & 0.233 \\
\hline Preeclampsia & $2(6.7)$ & $49(23.1)$ & 0.055 \\
\hline Thyroid disorders & $3(10.0)$ & $28(13.2)$ & 0.624 \\
\hline PROM & $1(3.4)$ & $26(12.3)$ & 0.189 \\
\hline Not treated ANS & $11(36.7)$ & $76(35.8)$ & 0.930 \\
\hline Oligohydramnios & $8(27.6)$ & $47(22.2)$ & 0.930 \\
\hline Primigravida & $17(56.7)$ & $144(67.9)$ & 0.224 \\
\hline Cesarean section & $24(80.0)$ & $200(94.3)$ & 0.009 \\
\hline \multicolumn{4}{|l|}{ Comorbidities } \\
\hline Apgar score less than 7 at 5 minutes & $17(63)$ & $67(31.6)$ & 0.006 \\
\hline Air leak syndrome & $2(6.7)$ & $8(3.8)$ & 0.462 \\
\hline \multicolumn{4}{|c|}{ The data are presented as medians (interquartile range) $n(\%)$. } \\
\hline \multicolumn{4}{|c|}{$\begin{array}{l}R O P \text { retinopathy of prematurity, } P R O M \text { premature rupture of the membranes, } A N S \text { antenatal steroid, } \\
B P D \text { bronchopulmonary dysplasia, } P D A \text { patent ductus arteriosus, } S C r \text { serum creatinine. }\end{array}$} \\
\hline \multicolumn{4}{|c|}{$\begin{array}{l}\text { a Small for gestational age corresponds to birth weight below the }-2 \text { z-score according to the } \\
\text { INTERGROWTH-21st standard. }\end{array}$} \\
\hline
\end{tabular}




\begin{tabular}{|c|c|c|c|}
\hline & $\begin{array}{l}\text { ROP } \\
(n=30)\end{array}$ & $\begin{array}{l}\text { No-ROP } \\
(n=212)\end{array}$ & $p$ value \\
\hline Pulmonary hemorrhage & $1(3.3)$ & $5(2.4)$ & 0.749 \\
\hline Pulmonary hypertension & $2(6.7)$ & $1(0.5)$ & 0.030 \\
\hline Respiratory distress syndrome & $30(100.0)$ & $198(93.4)$ & 0.228 \\
\hline Postnatal steroid use & $18(60.0)$ & $34(16.0)$ & $<0.001$ \\
\hline Duration of mechanical ventilation (days) & $20.5(11.8-27.3)$ & $3(2-8)$ & $<0.001$ \\
\hline Moderate-to-severe BPD & $7(23.3)$ & $12(5.7)$ & 0.002 \\
\hline Surgically treated PDA & $11(36.7)$ & $22(10.4)$ & $<0.001$ \\
\hline Low blood pressure within 7days after birth & $12(40.0)$ & $36(17.0)$ & 0.004 \\
\hline Seizure & $2(6.7)$ & $2(0.9)$ & 0.049 \\
\hline Severe brain injury ${ }^{b}$ & $6(20.0)$ & $12(5.7)$ & 0.009 \\
\hline Duration of total parenteral nutrition (days) & $23(16-34.3)$ & $11.5(7-18)$ & 0.002 \\
\hline Necrotizing enterocolitis & $2(6.7)$ & $5(2.4)$ & 0.210 \\
\hline High SCr & $21(70.0)$ & $42(19.8)$ & $<0.001$ \\
\hline Total transfusion & $4(2-5)$ & $1(0-2)$ & $<0.001$ \\
\hline Sepsis & $9(30.0)$ & $15(7.1)$ & $<0.001$ \\
\hline \multicolumn{4}{|c|}{ The data are presented as medians (interquartile range) $n(\%)$. } \\
\hline \multicolumn{4}{|c|}{$\begin{array}{l}R O P \text { retinopathy of prematurity, } P R O M \text { premature rupture of the membranes, } A N S \text { antenatal steroid, } \\
B P D \text { bronchopulmonary dysplasia, } P D A \text { patent ductus arteriosus, } S C r \text { serum creatinine. }\end{array}$} \\
\hline \multicolumn{4}{|c|}{$\begin{array}{l}\text { asmall for gestational age corresponds to birth weight below the }-2 \text { z-score according to the } \\
\text { INTERGROWTH-21st standard. }\end{array}$} \\
\hline
\end{tabular}

The incidence for most commodities was significantly higher in the ROP group than in the non-ROP group, except for air leak syndrome, massive pulmonary hemorrhage, RDS, and necrotizing enterocolitis.

In multivariable regression analysis, GA (odds ratio [OR] 0.38, 95\% confidence interval [Cl] $0.23-0.61 ; p<$ 0.001 ) and high SCr group (OR 4.68, 95\% Cl 1.10-19.90; $p=0.037$ ) were independent risk factors for ROP requiring treatment (Table 3$)$. 
Table 3

Multivariate logistic regression analysis of the factors underlying ROP requiring treatment.

\begin{tabular}{|c|c|c|}
\hline & OR $(95 \% \mathrm{Cl})$ & $p$ value \\
\hline Gestational age (weeks) & $0.38(0.23,0.61)$ & $<0.001$ \\
\hline Cesarean section & $0.20(0.03,1.33)$ & 0.096 \\
\hline Mechanical ventilation (days) & $1.07(1.00,1.14)$ & 0.051 \\
\hline Duration of total parenteral nutrition & $0.95(0.89,1.01)$ & 0.084 \\
\hline High SCr & $4.68(1.10,19.90)$ & 0.037 \\
\hline \multicolumn{3}{|c|}{$\begin{array}{l}\text { Adjusted for gestational age, birth weight, multiple gestations, male sex, preeclampsia, cesarean } \\
\text { section, Apgar score less than } 7 \text { at } 5 \text { minutes, pulmonary hypertension, postnatal steroid use, } \\
\text { mechanical ventilation, moderate-to-severe bronchopulmonary dysplasia, surgically-treated patent } \\
\text { ductus arteriosus, low blood pressure within } 7 \text { days after birth, seizure, severe brain injury, duration of } \\
\text { total parenteral nutrition, high serum creatinine, total transfusion, sepsis. }\end{array}$} \\
\hline \multicolumn{3}{|c|}{$O R$ odds ratio, $\mathrm{Cl}$ confidence interval, $S C r$ serum creatinine. } \\
\hline
\end{tabular}

\section{Discussion}

This study investigated the contribution of high SCr levels (reflecting abnormal renal function) in VLBW infants to the development of ROP requiring treatment during the first month of life. The incidence of ROP requiring treatment was higher in the high $\mathrm{SCr}$ group than in the normal $\mathrm{SCr}$ group.

Previous studies have reported the possibility of shared genetic, physiologic, and pathologic pathways between the kidney and eye. ${ }^{11,12}$ It is known that retinal vascularization and nephrogenesis are most active at the end of the second trimester and the beginning of the third trimester, and maturity end at term GA. ${ }^{13,14}$ Further, several studies have reported a local renin-angiotensin-aldosterone system in the retina, which affected the development of retinal diseases such as ROP. ${ }^{12}$ However, the relationship between abnormal renal function and ROP has not been elucidated due to the difficulty in diagnosing abnormal renal function in premature infants.

$\mathrm{SCr}$, but not renal injury, is commonly used as a surrogate marker of renal function. The current definition of acute kidney injury (AKI) is based on the changes in SCr and/or urine volume. However, in clinical practice, it is difficult to accurately measure urine output and non-oliguric AKI has been reported in newborns. ${ }^{15}$ In addition, this definition of AKI was not based on changes in physiological SCr during the early life of a newborn, especially preterm infants. 6,16,17 The change in $\mathrm{SCr}$ in early life is likely to include a combination of physiological and pathological components. Therefore, the normal range of $\mathrm{Cr}$ over time in stable VLBW infants without the risk factors affecting renal function was important to determine early $\mathrm{SCr}$ changes and their clinical utility to establish a diagnostic threshold for AKI. A recent study reported relative physiological changes in Cr levels of VLBW infants. ${ }^{7}$ 
In our study, the high SCr group was classified based on the 95th percentile value of SCr after 5 days of age for each GA. The SCr level of the neonate for at least $72 \mathrm{~h}$ after birth was known to reflect the maternal SCr level. ${ }^{18}$ Auron and Mhanna ${ }^{19}$ reported that $\mathrm{SCr}$ reached a plateau on day 5 after birth in VLBW infants. Bateman et al. ${ }^{7}$ reported that preterm infants of 25-27 weeks' GA also presented a transient peak of SCr on days 2 to 3 after birth. Thereafter, the SCr levels in all groups of infants decreased gradually for 6 to 8 weeks.

The high SCr group showed significantly lower GA, BW, and SCr at birth than the normal SCr group. In the present study, we demonstrated that the lower SCr level at birth in the high $\mathrm{SCr}$ group is associated with lower GA and BW, these findings were similar to those of a previous study by Go et al. ${ }^{20}$. A majority of infants in the high SCr group showed high values within the first two weeks of life. Thirty-one $(49.2 \%$, not shown in this article) infants had higher SCr levels in the second week than in the first week. In addition, as the use of inotropes within the first week of birth, the use of nephrotoxic drugs, and RDS incidence were reported in the high SCr group, it can be inferred that VLBW infants with high levels of SCr are affected by hemodynamic instability during the postnatal transition.

In Soonchunhyang Cheonan University Hospital, transfusion was performed according to the guidelines regulating pediatric transfusion. ${ }^{21}$ The high SCr group received the first blood transfusion earlier, and fewer blood samplings were performed before the first transfusion than the normal SCr group. Recently, Lust et al reported an association between early red cell transfusion and the development of severe ROP, independent of GA. ${ }^{3}$ These results might suggest that anemia is attributed to other etiologies in addition to blood loss, such as damage to RBC synthesis via Epo production and required transfusion in the high SCr group

The results of our present study showed that lower GA and high $\mathrm{SCr}$ group were independent risk factors for ROP requiring treatment. Low GA is known as one of the strongest risk factors for the development of ROP. ${ }^{1,22}$ To the best of our knowledge, this is the first study establishing the association between high $\mathrm{SCr}$ levels and ROP requiring treatment.

Further validation of the $\mathrm{SCr}$ reference ranges requires additional studies to determine the precise mechanism underlying the $\mathrm{SCr}$ elevation and its contribution to short-term and long-term complications.

Our present study had limitations; a large difference in the number of VLBW infants was observed among GA categories: 51 infants in GA 25-27 weeks, 94 in GA 28-29 weeks, and 97 in GA 30-32 weeks. In addition, this retrospective study was based on the medical records of infants admitted to the hospital. Therefore, we were unable to investigate the factors determining the glomerular filtration rate or tubular function, such as creatinine clearance or fractional excretion of sodium.

\section{Conclusions}


High SCr within the first 4 weeks after birth was one of the risk factors for ROP requiring treatment. Further studies are needed to elucidate the precise mechanism, treatment, and prevention of this condition.

\section{Declarations}

\section{Ethic approval and consent to participate:}

The study conformed to the ethical guidelines of the World Medical Association Declaration of Helsinki and was approved by the Institutional Review Board (IRB) of Soonchunhyang University Cheonan Hospital. Written informed consent was waived by IRB (No. 2020-02-026-002). This was a retrospective study that did not include subjects' personally identifiable information and met the consent exemption criteria.

\section{Consent for publication:}

Not applicable.

\section{Availability of data and materials:}

The datasets used and/or analysed during the current study are available from the corresponding author on reasonable request.

Competing interests: The authors declare that they have no competing interests.

Funding: This work was supported by Soonchunhyang University Research Fund.

\section{Author Contributions}

S.P.B. and S.S.K. made substantial contributions to conception and design. S.P.B., W.H.H., H.K., J.W.K., and S.Y.P. participated in the acquisition of data, or analysis and interpretation of data. S.P.B., S.S.K., and J.H.S. drafted the article or revised it critically for important intellectual content and gave final approval of the version to be published.

\section{Acknowledgements}

This work was supported by Soonchunhyang University Research Fund.

\section{References}

1. Hellström, A., Smith, L. E. \& Dammann, O. Retinopathy of prematurity. Lancet 382, 1445-1457 (2013).

2. Lundgren, P. et al. Duration of anaemia during the first week of life is an independent risk factor for retinopathy of prematurity. Acta Paediatr. 107, 759-766 (2018). 
3. Lust, C. et al. Early red cell transfusion is associated with development of severe retinopathy of prematurity. J. Perinatol. 39, 393-400 (2019).

4. Asada, N. Tubular immaturity causes erythropoietin-deficiency anemia of prematurity in preterm neonates. Sci. Rep. 8, 4448 (2018).

5. Nakagawa, M. et al. Impaired nephrogenesis in neonatal rats with oxygen-induced retinopathy. Pediatr. Int. 59, 704-710 (2017).

6. Askenazi, D. J., Ambalavanan, N. \& Goldstein, S. L. Acute kidney injury in critically ill newborns: what do we know? What do we need to learn? Pediatr. Nephrol. 24, 265-274 (2009).

7. Bateman, D. A. et al. Serum creatinine concentration in very-low-birth-weight infants from birth to 3436 wk postmenstrual age. Pediatr. Res. 77, 696-702 (2015).

8. Fierson, W. M. Screening examination of premature infants for retinopathy of prematurity. Pediatrics 131, 189-195 (2013).

9. International Committee for the Classification of Retinopathy of Prematurity The International Classification of Retinopathy of Prematurity revisited. Arch. Ophthalmol. 123, 991-999 (2005).

10. Good, W. V. Final results of the Early Treatment for Retinopathy of Prematurity (ETROP) randomized trial. Trans. Am. Ophthalmol. Soc. 102, 233-250 (2004).

11. Izzedine, H., Bodaghi, B., Launay-Vacher, V. \& Deray, G. Eye and kidney: from clinical findings to genetic explanations. J. Am. Soc. Nephrol. 14, 516-529 (2003).

12. Wilkinson-Berka, J. L., Agrotis, A. \& Deliyanti, D. The retinal renin-angiotensin system: roles of angiotensin II and aldosterone. Peptides 36, 142-150 (2012).

13. Roth, A. M. Retinal vascular development in premature infants. Am. J. Ophthalmol. 84, 636-640 (1977).

14. Ryan, D. et al. Development of the Human Fetal Kidney from Mid to Late Gestation in Male and Female Infants. EBioMedicine 27, 275-283 (2018).

15. Karlowicz, M. G. \& Adelman, R. D. Nonoliguric and oliguric acute renal failure in asphyxiated term neonates. Pediatr. Nephrol. 9, 718-722 (1995).

16. Lao, T. T., Loong, E. P., Chin, R. K. \& Lam, Y. M. Renal function in the newborn. Newborn creatinine related to birth weight, maturity and maternal creatinine. Gynecol. Obstet. Invest. 28, 70-72 (1989).

17. Guignard, J. P. \& Drukker, A. Why do newborn infants have a high plasma creatinine? Pediatrics 103, e49 (1999).

18. Filler, G., Guerrero-Kanan, R. \& Alvarez-Elías, A. C. Assessment of glomerular filtration rate in the neonate: is creatinine the best tool? Curr. Opin. Pediatr. 28, 173-179 (2016).

19. Auron, A. \& Mhanna, M. J. Serum creatinine in very low birth weight infants during their first days of life. J. Perinatol. 26, 755-760 (2006).

20. Go, $\mathrm{H}$. et al. Neonatal and maternal serum creatinine levels during the early postnatal period in preterm and term infants. PLoS One 13, e0196721 (2018). 
21. Roseff, S. D., Luban, N. L. \& Manno, C. S. Guidelines for assessing appropriateness of pediatric transfusion. Transfusion 42, 1398-1413 (2002).

22. Chang, J. W. Risk factor analysis for the development and progression of retinopathy of prematurity. PLoS One 14, e0219934 (2019).

\section{Figures}

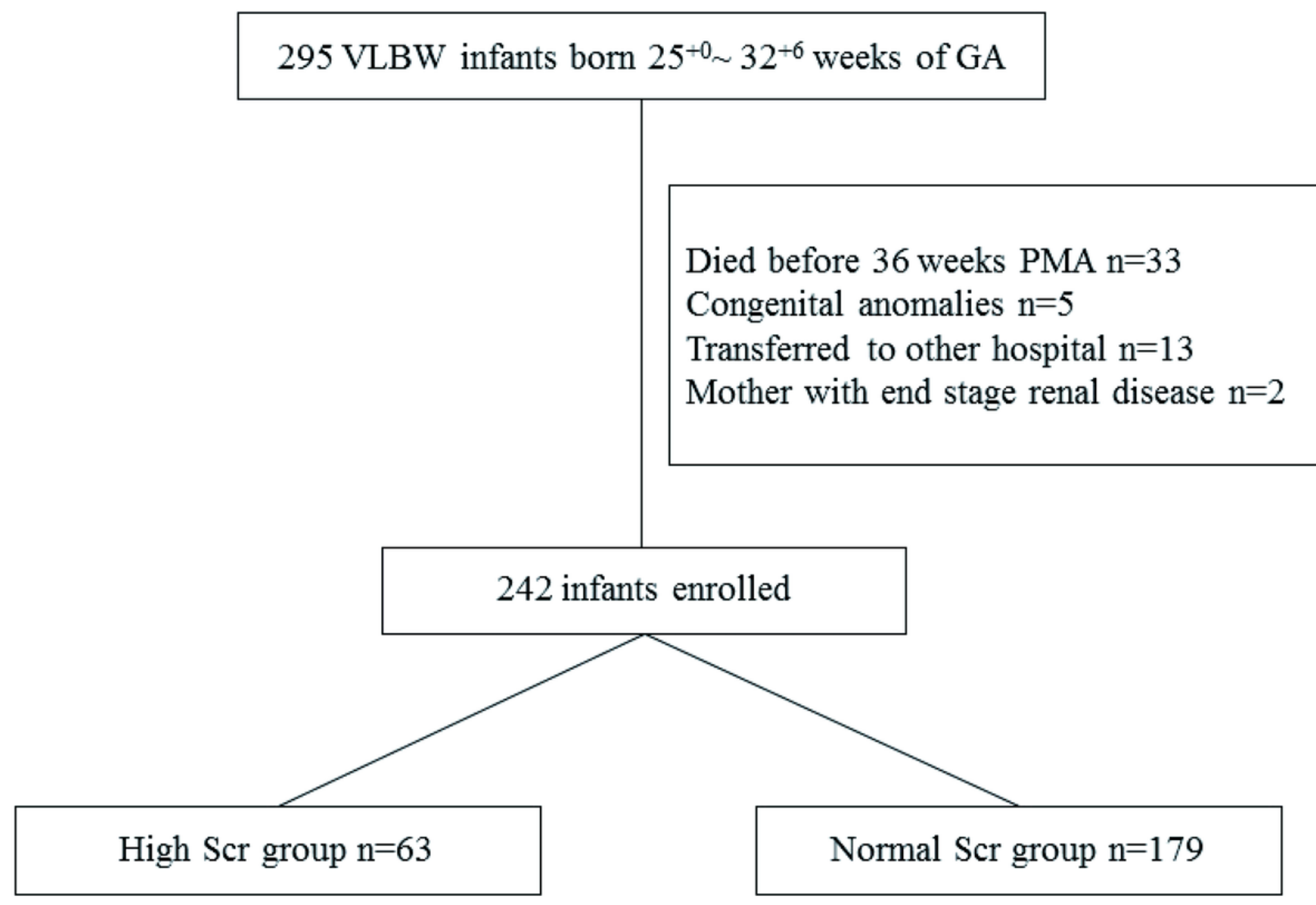

\section{Figure 1}

Flow chart of the study group. VLBW very low birth weight, GA gestational age, PMA postmenstrual age, SCr serum creatinine. 
a. GA 25-27 weeks
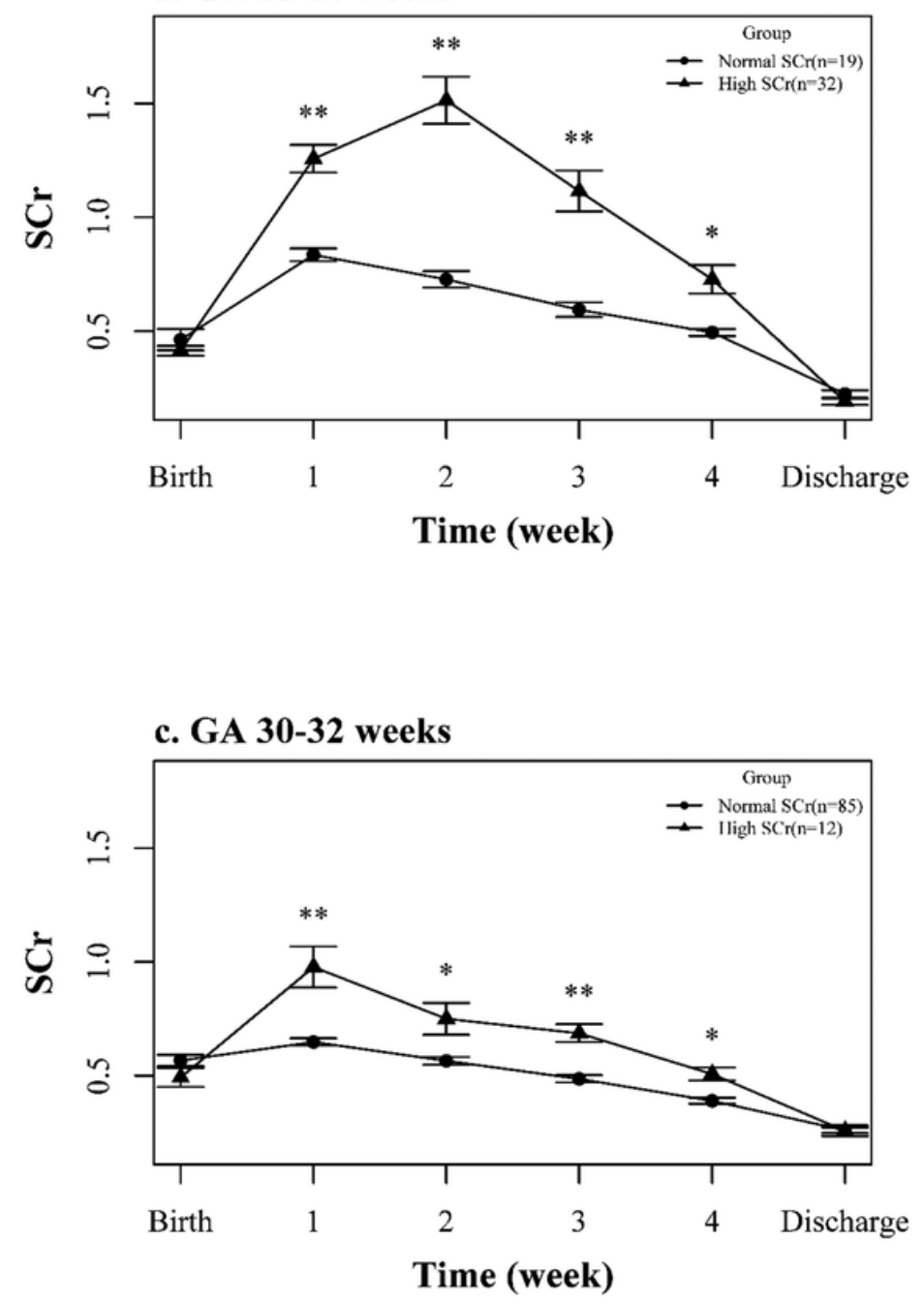

b. GA 28-29 weeks
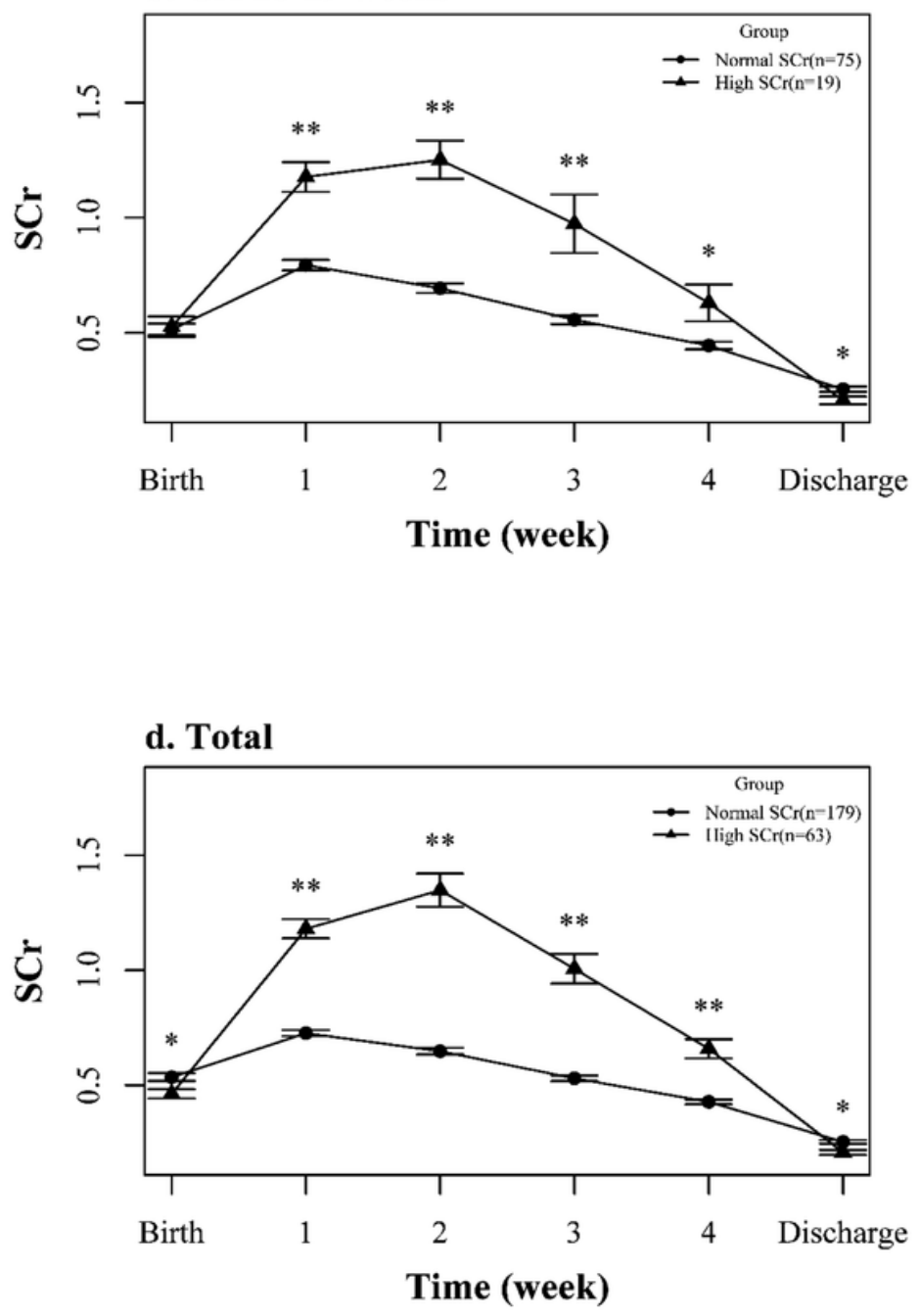

Figure 2

Serum creatinine (SCr) levels from birth to discharge, in each gestational age (GA). ${ }^{*} p<0.05 .{ }^{*} \mathrm{p}<0.001$. 